\title{
Beneluxa: What are the Prospects for Collective Bargaining on Pharmaceutical Prices Given Diverse Health Technology Assessment Processes?
}

\author{
James F. O'Mahony ${ }^{1}$ \\ Published online: 8 March 2019 \\ (c) Springer Nature Switzerland AG 2019
}

The Beneluxa collaboration is an initiative aimed at securing sustainable access to new medicines. It was established in April 2015 by Belgium and the Netherlands. Luxembourg and Austria have joined since. Ireland became a member in June 2018. Beneluxa's stated goal is to ensure "timely access and affordability of medicines" [1]. It aims to achieve this through five principal activities: joint horizon scanning; mutual recognition of heath technology assessments (HTAs); sharing policy expertise and best practice; enhanced bargaining power through joint price negotiation; and, improved price transparency [1]. The initiative's organisational structure and member mutual responsibilities are documented in their terms of reference [2].

Ireland's admission to the group was welcomed by Irish Minister for Health, Simon Harris, with claims that Beneluxa will assist Ireland by "ensuring that medicines can be sourced at a price that is affordable and sustainable in the context of the ever competing demands for resources rights [sic] across our health service" [3]. This commentary considers why such optimism might be misplaced due to the potential challenges of collective bargaining and mutual HTA recognition among states with different HTA decision processes. It explains why political involvement in decision making will likely compromise collective action. It concludes with an outline of what positive benefits could stem from methods collaboration between members. While the editorial is written from an Irish perspective, the issues apply to other members of the initiative.

James F. O’Mahony

jfomahon@tcd.ie

1 Centre for Health Policy and Management, Trinity College Dublin, Dublin, Ireland

\section{Divergence in Health Technology Assessment (HTA) Methods}

Part of the rationale for Beneluxa is the idea that smaller nations lack the bargaining power required to negotiate down prices with large pharmaceutical companies. The proposed solution appears to be that small countries join together and negotiate collectively on prices to achieve better value. This idea seems to make sense, but it is worth considering the technical details further. A natural question to then ask is, are countries going to negotiate collectively on a common drug price for all member nations? Assuming that collective bargaining does imply a common price, this in turn prompts the question, how might different countries agree on what is an acceptable common price given the current differences in HTA processes among Beneluxa members? Some of the fundamental differences in HTA processes include discount rates, the choice of perspective, health-related quality-of-life weighting schemes, and the presence of clear cost-effectiveness thresholds.

Intertemporal discounting is an obvious example of HTA methods divergence within Beneluxa. Both Ireland and Austria are relatively high discounters, at 5\% [4, 5]. Belgium and the Netherlands both use differential discounting, applying $3 \%$ and $1.5 \%$ and $4 \%$ and $1.5 \%$ to costs and health effects, respectively [6]. In practice, this means there may be substantial divergence between Beneluxa members on acceptable prices for many interventions, especially preventative interventions and those with long-term benefits.

The perspective of analysis also varies between Beneluxa members. Irish HTA guidelines require the health system perspective in the reference case [4], as do the Belgian guidelines (although they also recommend the inclusion of patient co-pays) [7]. This contrasts with Dutch guidelines, which require the broader societal perspective [8]. The Austrian HTA guidelines have not been updated since 2006 and do not definitively state what perspective should be used [5]. 
Luxembourg currently has no HTA guidelines. Accordingly, there is both variation and lack of clarity over the appropriate perspective to apply within Beneluxa members.

A notable recent change in the Dutch guidelines is the inclusion of unrelated future healthcare costs when considering mortality-reducing interventions [8]. For example, Dutch analyses now must include the cost of anticipated future interventions such as hip replacements when considering interventions that reduce mortality, such as heart surgery [9]. This is a very fundamental departure from typical HTA methods to date and is at variance with guidelines in other Beneluxa members.

The weighting of health gains can also vary between countries. Irish guidelines do not provide special weightings for health gains based on disease severity or rarity [4] (although decision makers may of course implicitly apply such weightings behind closed doors). By contrast, the Netherlands explicitly includes the concepts of proportionate shortfall in its weighting of healthcare interventions to capture equity concerns arising from variations in disease severity $[9,10]$. Irrespective of whether the Dutch proportionate shortfall scheme is justified or operationally consistent, it clearly represents another profound divergence in the weighting of health between the Netherlands and the other Beneluxa members, including Ireland.

Finally, an obvious and fundamental part of the HTA decision framework is the use of cost-effectiveness thresholds. Ireland is the only Beneluxa member that has a clear threshold, which is currently $€ 45,000$ per quality-adjusted life-year (QALY) [11]. The Dutch do not employ a single threshold but suggest a wide range of $€ 20,000-80,000$ per QALY, depending on disease severity [10].

The cost effectiveness of technologies may, of course, also vary between countries for reasons other than methodological divergence. Simple differences in the costs of related medical services, current practice, and health system configuration may also lead to varying conclusions, even between western European nations of similar per capita income.

\section{Implications for Collective Decision Making and HTA Sovereignty}

These important technical differences between HTA processes and health systems mean that large differences (or at least significant ambiguities) may emerge between Beneluxa members in terms of what are considered cost-effective prices, and how these differences might be reconciled is not yet clear. This poses a problem for one of Beneluxa's objectives of speeding up access to new drugs: waiting for all members to conclude HTAs and then agree a mutually acceptable common price will surely take longer than individual assessment by each member state.
The question of methods divergence is also relevant to the issue of mutual HTA recognition. Current Beneluxa documents indicate that mutual HTA recognition may involve one country adopting parts or all of an HTA conducted in another member state [12]. While partial adoption seems feasible, for example of the estimation of core clinical effectiveness of an intervention, full adoption does not. This is because full adoption requires accepting those portions of the HTA relating to valuation in terms of health-related quality of life and the net health benefit when accounting for opportunity costs as represented by the threshold.

Full mutual recognition may lead to conflicts between analyses that reach opposing conclusions on the cost effectiveness of the same interventions. HTA controls could effectively become weakened if an intervention is accepted for reimbursement once it is found to be cost effective in any one of the Beneluxa member states. Indeed, patient advocacy groups may lobby for access in one member state based on an analysis conducted in another. Accordingly, it would be useful to clarify the sensible limits of mutual HTA recognition. This would help dispel fears of such a 'watering down' of HTA.

Mutual recognition of HTA also presents a potential constraint on accountability. I have previously written on my concerns regarding the methods applied in official HTAs of cancer screening published by Ireland's national HTA authority [13-15]. Analytical choices in HTA are likely to remain contentious when reimbursement decisions are contingent on them. The obligation to recognise HTAs conducted by foreign agencies appears to enhance the probabilities that such methods disputes will arise. Moreover, mutual recognition could compromise the ability to identify, challenge, and correct such instances if the body and analysts responsible are overseas.

This concern relating to the reliance on foreign HTAs reflects a broader worry about a potential loss of sovereignty over HTA methods more generally. HTA methods develop over time, hopefully through a thoughtful process of debate. For example, Ireland's Health Information and Quality Authority (HIQA) have enhanced Ireland's HTA guidelines in a series of revisions following public consultation since their first publication in 2010. Currently there seems little opportunity (or clear mandate) for Irish health economists to influence the refinement of HTA guidelines in other Beneluxa members. While this may seem like an academic concern, one only needs to reflect on some of the profound differences in methods outlined above to see why the question of methods sovereignty matters.

\section{The Political Reality of Price Negotiations}

This consideration of the possible implications of divergent HTA processes possibly reflects an abstract, academic approach to pharmaceutical pricing. The 
behind-closed-doors reality of price negotiations might be much more rough-and-ready horse trading and often only tenuously related to cost-effectiveness ratios and thresholds. Accordingly, the concerns of HTA methods divergence I have outlined may be largely overstated. However, this does not overcome a second potential problem of collective bargaining on pharmaceutical prices, which relates to political pressure and the opportunities to break ranks with Beneluxa agreements.

I would argue that the current weaknesses of HTA processes in achieving sustainable prices has much more to do with a lack of political support for rational rationing than any technical constraints on appraisal capacity. We can see examples where politicians contradict the advice of national HTA experts and interventions are apparently funded at prices far in excess of what would be cost-effective [13]. Similarly, within oncology, we repeatedly see examples of drugs that are funded without any publicly published indication that the cost-effectiveness threshold had been met [16].

The explanation for such threshold-breaking approvals may just be a fundamental failure of current appraisal processes: maybe our present HTA methods simply do not adequately reflect society's relative valuation of the health of the patients seeking new interventions and the health of those other patients elsewhere that bear the opportunity cost. However, what seems a more plausible explanation is that political pressure for reimbursement is driving decisions that are both highly inefficient and grossly inequitable from a cost-effectiveness perspective.

The persistence of such political pressure to fund specific interventions will compromise prospects for collective bargaining. The appeal to a supra-national decision-making collective may offer some political cover for elected decision makers seeking to deflect attention from withholding reimbursement, but popular support for specific interventions will ultimately still provide an incentive for politicians to break ranks with Beneluxa members and grant reimbursement. For collective price bargaining to work, elected decision makers will have to remove themselves from the reimbursement decision process. I cannot comment on the prospect of this happening in other Beneluxa members, but I doubt that membership of the initiative alone will provide Ireland with the necessary discipline to achieve this.

\section{Reasons for Optimism and Prioritisation of Effort}

It would be a mistake to only be pessimistic regarding the potential for trans-national collaboration on HTA. My commentary has focused on the difficulties of collaborating on common cost-effective prices. Of course, good scope exists for collaboration on common estimation of intervention effectiveness, especially where such estimates are more closely related to clinical effectiveness and less sensitive to methodological choices regarding valuation. In this sense, the prospects for partial mutual HTA recognition seem good. More generally, the prospects for sharing analytical expertise between member nations also seem good: dialogue between HTA authorities should enhance national capacities and spread best practice.

While Beneluxa may face some practical constraints on collective bargaining and mutual HTA recognition, there are other objectives it could usefully work towards. I suggest that all countries need to make serious attempts at estimating empirical cost-effectiveness thresholds that adequately reflect the opportunity costs borne by many thousands of patients waiting for capacity-constrained services [17, 18]. Reflecting this, I would like to see Beneluxa members consider decision processes that more strictly balance the needs of funding new interventions versus the patients in existing services. For instance, the Irish Health Act of 2013 states that the public health system should give regard to "the cost effectiveness of meeting health needs by supplying the item concerned rather than providing other health services" [19]. The current Irish threshold and appraisal process in Ireland appears not to balance those needs in any way that can be considered technically or ethically adequate. I also see ample scope for evidence-based reform of discount rates along the lines recently achieved in Canada [20, 21]. If Beneluxa could direct its efforts towards reform of HTA processes along these lines, then I think it could be a meaningful force for change in the fair allocation of scarce healthcare resources.

In conclusion, significant divergence between HTA methods between Beneluxa members appears an impediment to collective bargaining on common prices and full mutual HTA recognition. Even if common prices can be achieved, political incentives will remain for decision makers to break ranks from Beneluxa. Better prospects remain for partial HTA recognition regarding clinical effectiveness and the sharing of expertise. Beneluxa could also be a vehicle for the necessary rebalancing of HTA methods regarding true opportunity costs. Although the initiative is likely to face challenges, it should be supported in its efforts to achieve more sustainable healthcare.

\section{Compliance with Ethical Standards}

Conflict of Interest JFO'M has no conflicts of interest that are directly relevant to the content of this editorial.

\section{References}

1. Beneluxa. Collaboration 2018 [15-2-2019]. http://www.beneluxa. org/collaboration. Accessed 15 Feb 2019. 
2. Beneluxa. The Beneluxa initiative on pharmaceutical policyterms of reference 2018. http://www.beneluxa.org/sites/beneluxa. org/files/2018-10/180622\%20Terms\%20of\%20Reference\%20Ben eluxa\%20Initiative.pdf. Accessed 15 Feb 2019.

3. Department of Health. Minister Harris signs international agreement aimed at securing affordable and timely access to new medicines for Irish patients: 'Department of Health; 2018. https:// health.gov.ie/blog/press-release/minister-harris-signs-internatio nal-agreement-aimed-at-securing-affordable-and-timely-acces s-to-new-medicines-for-irish-patients/. Accessed 15 Feb 2019.

4. HIQA. Guidelines for the Economic Evaluation of Health Technologies in Ireland: Health Information and Quality Authority; 2018. https://www.hiqa.ie/sites/default/files/2018-01/HIQA_ Economic_Guidelines_2018.pdf. Accessed 15 Feb 2019.

5. IPF. Guidelines on Health Economic Evaluation: Consensus Paper: Institut für Pharmaökonomische Forschung; 2006. http:// www.ipf-ac.at/fileadmin/template/PDF\%20alt/Konsens_Guide lines_en.pdf. Accessed 15 Feb 2019.

6. Attema AE, Brouwer WB, Claxton K. Discounting in economic evaluations. PharmacoEconomics. 2018;36(7):1-14. https://doi. org/10.1007/s40273-018-0672-z.

7. KCE. Belgian guidelines for economic evaluations and budget impact analyses: second edition: Belgian Healthcare Knowledge Centre; 2012. https://kce.fgov.be/sites/default/files/atoms/files/ KCE_183_economic_evaluations_second_edition_Report_updat e.pdf. Accessed 15 Feb 2019.

8. ZIN. Guideline for economic evaluations in healthcare Zorginstituut Nederland; 2016. https://english.zorginstituutnederla nd.nl/binaries/zinl-eng/documents/reports/2016/06/16/guidelinefor-economic-evaluations-in-healthcare/Guideline+for+econo mic+evaluations+in+healthcare.pdf. Accessed 15 Feb 2019.

9. Versteegh M, Knies S, Brouwer W. From good to better: new Dutch guidelines for economic evaluations in healthcare. PharmacoEconomics. 2016. https://doi.org/10.1007/s40273-016-0431-y.

10. ZIN. Cost-Effectiveness in Practice: Zorginstituut Nederland; 2015. https://english.zorginstituutnederland.nl/binaries/zinl-eng/ documents/reports/2015/06/16/cost-effectiveness-in-practice/ Cost-effectiveness+in+practice.pdf. Accessed 15 Feb 2019.

11. O'Mahony JF, Coughlan D. The Irish cost-effectiveness threshold: does it support rational rationing or might it lead to unintended harm to Ireland's health system? PharmacoEconomics. 2016;34(1):5-11. https://doi.org/10.1007/s40273-015-0336-1.

12. Beneluxa. HTA 2018 [19-2-2019]. http://www.beneluxa.org/hta. Accessed 15 Feb 2019

13. O'Mahony JF. HIQA's perspective on the challenges posed by evaluations of screening programs: a reply. Value in Health. 2019;22(1):136-8. https://doi.org/10.1016/j.jval.2018.06.021.

14. O'Mahony JF, Normand C. HIQA's CEA of breast screening: pragmatic policy recommendations are welcome, but ACERs reported as ICERs are not. Value Health. 2015;18(8):941-5. https ://doi.org/10.1016/j.jval.2015.08.009.

15. O'Mahony JF. Cost-effectiveness of population-based screening for colorectal cancer. Br J Cancer. 2013;108(5):1209.

16. NCCP. Cancer drugs approved for reimbursement: National Cancer Control Programme; 2019. https://www.hse.ie/eng/services/ list/5/cancer/profinfo/medonc/cdmp/new.html. Accessed 15 Feb 2019.

17. Chen TC, Wanniarachige D, Murphy S, Lockhart K, O'Mahony J. Surveying the cost effectiveness of the 20 procedures with the largest public health services waiting lists in Ireland: Implications for Ireland's cost-effectiveness threshold. Value Health. 2018. https://doi.org/10.1016/j.jval.2018.02.013.

18. Edney LC, Afzali HHA, Cheng TC, Karnon J. Estimating the reference incremental cost-effectiveness ratio for the Australian health system. PharmacoEconomics. 2018;36(2):239-52. https:// doi.org/10.1007/s40273-017-0585-2.

19. Oireachtas Éireann. Health (pricing and supply of medical goods) Act 2013, Schedule 3: Part 3.b 2013. http://www.irishstatuteboo k.ie/pdf/2013/en.act.2013.0014.pdf. Accessed 22 Feb 2019.

20. Paulden M, Galvann V, Chakraborty S, Kudinga B, McCabe C. Discounting and the evaluation of health care programs. https:// www.cadth.ca/sites/default/files/pdf/CP0008_Economic_Evalu ation_Guidelines_Discount_Rate_Report.pdf. Accessed 1 Oct 2018.

21. CADTH. Guidelines for the economic evaluation of health technologies: Canada; 4th Edition: Canadian Agency for Drugs and Technologies in Health; 2017. https://www.cadth.ca/sites/defau lt/files/pdf/guidelines_for_the_economic_evaluation_of_healt h_technologies_canada_4th_ed.pdf. Accessed 19 Feb 2018. 